\title{
LIFE CYCLE ASSESSMENT OF TECHNICAL BUILDING SERVICES OF LARGE RESIDENTIAL BUILDING STOCKS USING SEMANTIC 3D CITY MODELS
}

\author{
H. Harter ${ }^{1, *}$, B. Willenborg ${ }^{2}$, W. Lang ${ }^{1}$, T. H. Kolbe ${ }^{2}$ \\ ${ }^{1}$ Institute of Energy Efficient and Sustainable Design and Building, \\ Technical University of Munich (TUM), Munich, Germany - (hannes.harter, sekretariat.enpb.bgu)@ tum.de \\ ${ }^{2}$ Chair of Geoinformatics, Technical University of Munich (TUM), Munich, Germany - (b.willenborg, thomas.kolbe)@ tum.de
}

Commission VI, WG VI/4

KEY WORDS: Life Cycle Assessment (LCA), Technical Building Services, Energy Demand Calculation, Sustainable Building, Sustainable City Development, Semantic 3D City Models, CityGML, Urban Simulation

\begin{abstract}
:
Reducing the demand for non-renewable resources and the resulting environmental impact is an objective of sustainable development, to which buildings contribute significantly. In order to realize the goal of reaching a climate-neutral building stock, it must first be analyzed and evaluated in order to develop optimization strategies. The life cycle based consideration and assessment of buildings plays a key role in this process. Approaches and tools already exist for this purpose, but they mainly take the operational energy demand of buildings and not a life cycle based approach into account, especially when assessing technical building services (TBS). Therefore, this paper presents and applies a methodical approach for the life cycle based assessment of the TBS of large residential building stocks, based on semantic 3D city models (CityGML). The methodical approach developed for this purpose describes the procedure for calculating the operational energy demand (already validated) and the heating load of the building, the dimensioning of the TBS components and the calculation of the life cycle assessment. The application of the methodology is illustrated in a case study with over 115,000 residential buildings from Munich, Germany. The study shows that the methodology calculates reliable results and that a significant reduction of the life cycle based energy demand can be achieved by refurbishment measures/scenarios. Nevertheless, the goal of achieving a climate-neutral building stock is a challenge from a life cycle perspective.
\end{abstract}

\section{INTRODUCTION}

Worldwide, buildings and construction account for about $35 \%$ of final energy consumption and are responsible for almost $40 \%$ of energy related carbon dioxide $\left(\mathrm{CO}_{2}\right)$ emissions. Buildings thus account for $30 \%$ (22\% residential buildings) of global final energy consumption and $28 \%$ (17\% residential buildings) of global energy-related $\mathrm{CO}_{2}$-emissions by sector (UN Environment and IAE, 2017).

These numbers clearly indicate the urgent need to cut down energy consumption and $\mathrm{CO}_{2}$-emissions of the worldwide building stock. For that reason, the European Union has set the goal to achieve a climate-neutral building stock in its 2050 long-term strategy (EU Commission, 2018). However, it must be kept in mind, that these numbers and goals generally only reflect the energy consumption and $\mathrm{CO}_{2}$-emissions related to the operation of buildings. All energy consumptions and $\mathrm{CO}_{2}$-emissions resulting from life cycle stages before and after the building's use stage are generally not taken into account.

With tightening regulations concerning the reduction of building energy consumption, e.g. the Energy Performance of Building Directive (EU Commission, 2018) on the European level, or the Energy Saving Ordinance (EnEV) (German Federal Ministry of EAE, 2013) on the German national level, minimum energy efficiency standards for (non-)residential buildings are defined. The introduction of these regulations led to a decrease in energy consumption during the use stage of buildings. However, the decreasing energy consumption in the use stage is related, for example, to an increasing use of insulation materials and efficient, more complex components of the

\footnotetext{
* Corresponding author
}

TBS (but with lower output from the heat generators), or to the trend towards reducing building automation and lowering energy consumption through the use of more passive building measures (orientation of buildings, natural ventilation, indoor light control). In both cases this leads to more material resources beeing needed to fulfill the task of increasing energy efficiency and decreasing $\mathrm{CO}_{2}$-emissions in the buildings use stage. Thus, it can happen that for buildings, that have a very low energy consumption in the use stage, it is no longer the energy consumption in this stage that accounts for the largest share over the entire life cycle, but rather the life cycle phases before and after the use of the building (Cabeza et al., 2014). Consequently, when talking about sustainable building or city development, the ecological and energetic performance of buildings must be evaluated and analyzed over the whole life cycle. For this purpose, Life Cycle Assessment (LCA) methods can be used. However, the implementation of LCA has not yet been made mandatory in legislation at neither the European nor German national level. For this reason, a LCA for buildings is very rarely calculated in practice and is hardly included in the decision-making process of building planning. In addition, even if LCAs are performed for buildings, in most cases this is only done on the basis of a single building considering only the building construction, without consideration of the technical building services (TBS). As life cycle based analysis allows for the identification of savings potentials and to support political decision making regarding regulations, it is important to calculate LCAs for large building stocks.

This study presents a methodological approach for an automated calculation of life cycle based energy assessment of TBS of large residential building stocks based on semantic 3D city models according to the CityGML standard. 


\subsection{Related work}

The use of semantic 3D city models for energetic considerations and assessment of the building stock is an active field of research. Several projects are based on the EnergyADE, an extension of the CityGML standard for urban energy modeling and simulation (Nouvel et al., 2015a).

In his $\mathrm{PhD}$ thesis Kaden developed EnEV-compliant methods (German Federal Ministry of EAE, 2013) for the estimation of the heat demand and saving potentials by refurbishing as well as for the estimation of electricity and warm water demand of residential buildings, based on the Energy Atlas of the City of Berlin. The input and energy demand values were modeled according to the EnergyADE (Kaden, 2014). In 2018, the work of Kaden was re-implemented using the software FME by Safe Software resulting in a fully automated workflow for building energy demand estimation. Moreover, a solar potential analysis tool was included to improve the energy demand estimation with more realistic solar energy estimations that include local climate conditions and the surrounding 3D topography (Fuchs, 2018, Willenborg et al., 2017).

Another example based on CityGML's EnergyADE is the urban energy simulation platform SimStadt. It offers a highly modular and flexible workflow-driven architecture. Its first version contained workflows for solar and PV potential analysis, energy demand and $\mathrm{CO}_{2}$ emission calculation, and refurbishment scenario generation and simulation (Nouvel et al., 2015b).

At Ecole Polytechnique Fédérale de Lausanne (EPFL) a building energy simulation database using CityGML EnergyADE was developed, including the integration of outdoor human comfort, urban micro-climate and its impact on human activities and well-being (Coccolo et al., 2016, Walter, Kämpf, 2015). Another approach offering dynamic simulation of the heat demand using the simulation framework Modelica was presented at RWTH Aachen. CityGML data of more than 2,800 buildings were enriched with statistical data and then converted to a Modelica model for the simulation (Remmen et al., 2016).

One of the few tools which offer simulations on city-scale is City Building Energy Saver (CityBES), a web-based data and computing platform, focusing on energy modeling and analysis of a city's building stock. CityBES uses CityGML to represent and exchange 3D city models and employs EnergyPlus to simulate building energy use and savings from energy efficient retrofits (Chen et al., 2017).

The Urban Modeling Interface (UMI) (Reinhart et al., 2013), developed at the Massachusetts Institute of Technology, is one of the few tools that can perform analyses at the city and neighborhood level, using a life cycle-based approach. However, the LCA does not go into detail about the TBS.

\subsection{Distinction from other work}

The existing tools and models are mainly specialized in calculating the energy demand during the building's use stage on the building block or city quarter level. Approaches for LCA do exist, but only with the help of a large number of building specific input parameters for the assessment, which make extrapolation to large existing building stocks difficult. Furthermore, none of these tools allow for the important life cycle based assessment of TBS. As described above, semantic 3D city models are used for urban energy simulations in different ways. Many applications use the city model data as an input for existing tools based on Modelica or Energy Plus. However, only a few approaches use the city model as a data integration platform and export the simulation results back to the model, which offers various benefits that will be discussed later. Moreover, most applications are evaluated using rather small data sets that only contain a few buildings. Bigger studies with several thousands of buildings or even at the city scale are rare.

\section{THEORETICAL BACKGROUND}

The method introduced in this work is based on a series of standards and existing tools, which are briefly listed in the following sections.

\subsection{Standards and tools for building energy and LCA}

The methodical approach for calculating the energy demand, heating load and dimensioning of TBS components is based on the standards and norms listed in the following reference. In the Method section, the associated standards and norms are listed again for each defined calculation step (DIN EN ISO 14040:2009-11, 2009, German Federal Ministry of EAE, 2013, DIN EN 15978:2012-10, 2012, DIN V 4108-6:2003-06, 2003, DIN V 4701-10:2003-08, 2003, DIN EN 12831-1:2017-09, 2017, DIN V 18599-5:2018-09, 2018, DIN V 18599-8:201809, 2018). For the LCA calculation the Ökobaudat database is used. With the Ökobaudat platform , the German Federal Ministry of the Interior, Building and Community provides stakeholders with a standardised database for the LCA of buildings. At the centre of the platform is the online database with LCA data sets on building materials, construction, transport, energy and disposal processes. This database is used for all LCA related calculations in this study (Federal Ministry of IBC, 2020).

\subsection{Semantic 3D City Models}

Semantic 3D city models describe the spatial, visual, and thematic aspects of the most common objects of cities and landscapes. The real world objects are decomposed and classified according to a semantic data model, that represents them in an ontological structure by thematic classes with attributes including their aggregations and interrelations. CityGML is an international standard by the Open Geospatial Consortium (OGC) and an open data model and encoding specification for representing and exchanging semantic 3D city models (Kolbe, 2009, Open Geospatial Consortium, 2012).

Today, CityGML is widely adopted and offers a good variety of tools to edit, analyze and visualize 3D city model data, that increasingly becomes available, in many cases as open data. A study from 2015 identified more than 29 use cases including more than 100 applications of 3D city models (Biljecki et al., 2015). The method and implementation introduced in the following is based on citygml4j $j^{1}$, an open source library reflecting the CityGML data model to the programming language Java. Moreover, the SharedWallSurface calculator developed by Sindram for Kaden (Kaden, 2014) and the Voluminator 2.0 (Sindram et al., 2016) are integrated for shared wall surface and building volume calculation. For creating 3D browser visualizations of the city model data and the method results the open source tool chain of the 3D City Database, the 3D City DB Importer/Exporter and the 3D City DB Web-Map-Client is applied (Yao et al., 2018).

\section{METHOD}

The presented method allows the life cycle based energy and environmental assessment of the TBS of large residential building stocks. A life cycle based energy and environmental assessment means, in the scope of this study, that the energy demand 
and emissions of the manufacturing (A1-A3), use (B4 \& B6) and end-of-life (EOL) (C2 \& C4) stages, according to DIN EN 15978 (DIN EN 15978:2012-10, 2012) of the TBS components are calculated and considered for the assessment. These LCA stages have been selected based on the data available in the Ökobaudat database, because consistent data is available for all selected LCA stages across all TBS components considered. The calculation of further LCA stages can be carried out analogously to the methodology described here, insofar as consistent data is available for the new LCA stage for all TBS components. The implementation of the LCA is based on the principles defined in DIN 14040 (DIN EN ISO 14040:2009-11, 2009). To achieve this, a methodological approach based on a few input data and definitions was developed. In the following, the main steps of the method and related standards are briefly described. The methodology was implemented in Java to create a usable tool. We named our developed tool urbi+ (urban $i$ mprovement + ) and use this name for further explanations in the text. In the calculation of large residential building stocks all energy demand, heating load and LCA calculations are carried out iteratively for each defined scenario for each residential building to be considered. In turn, this means that theoretically the life cycle based energy and environmental assessment of individual buildings can also be carried out using this method.

\subsection{Assumptions}

Before the individual methodological steps are explained, the following assumptions are made:

1) The Energy Demand Calculation and Heating Load Calculation are based on a single zone model. No building specific floor plan or zoning is used for the calculations, since this information is generally not available on a large building stock level.

2) Since the information on the refurbished standard of buildings is also generally not available, we assume that the energetic standard of the building, described by U-values, refers to its year of construction.

3) The energy demand calculation refers to the German Energy Saving Ordinance (EnEV) and therefore to DIN V 4108-6 and DIN V 4701-10 (used for energy demand calculation of residential buildings). Specifically, the heating period procedure is chosen as an approach within DIN V 4108-6. The length of the heating period is defined in the norm to 185 days.

4) The CityGML model used must be available in level of detail 2 (LoD2). This means, that the cubature of the building, including the roof shape, is available, but no information about windows or internal walls, etc. is given.

5) Underground car parks are excluded from the calculation. It is assumed that they are not thermally relevant/not heated. 6) In the refurbishment scenario it is assumed that the cubature of the buildings does not change, i. e. that there is no increase in height (urban redensification) and that no additional new buildings are added. All buildings are assumed to be refurbished and not demolished and rebuilt. An in depth refurbishment of buildings has proven to be the more ecological and less energyintensive option (Weiler et al., 2017).

7) The refurbishment of wall, ground and roof surfaces is represented by the improvement of the U-values. When refurbishing the TBS components, it is assumed that all components are replaced completely.

8) In case of refurbishment of a large building stock, the average of the energy systems defined for the entire building stock is used for the iterative calculation at building level. This means that if $80 \%$ of the residential buildings of the considered build- ing stock are heated with gas boilers and $20 \%$ with oil boilers, then exactly this percentage distribution of energy systems is used for all calculations at building level. Similarly, the respective primary energy factors (PEF) are used to calculate the primary energy demand (PED).

9) To distribute the refurbishment of all considered residential buildings over the period of the refurbishment scenario, a sequence of refurbishment is defined. The sequence results from a three-dimensional decision space between the building's year of construction, specific primary energy heating demand and absolute primary energy heating demand. The sequence is based on the fact that the oldest buildings with the highest specific and absolute heating requirement are refurbished first and are then graded in a similar way. In addition, the total number of buildings to be refurbished is divided by the development period to obtain the number of buildings to be refurbished per year.

10) The PEF required to calculate the PED can be adjusted over the development period. The PEF does not change abruptly in the course of a building refurbishment, but adapts gradually over time by calculating the difference between the old and new $\mathrm{PEF}$, distributed over the entire period.

11) When calculating the LCA of the TBS, the buildings that were refurbished first during the refurbishment period may require further replacement of components within the development period. If, for example, a reference service life (RSL) of 15 years is assumed for an instantaneous water heater, then in year 16 of the development period, the water heaters of the buildings refurbished in year one of the development period are replaced, insofar as they are installed in those buildings. The energy demand for the EOL and manufacturing stage of the new water heaters and the resulting emissions are calculated in LCA stage B4 and included in the energy balance of the 16th year of the development period. In the scope of this research the RSLs are defined based on the sustainable building assessment system (BNB) (Federal Ministry of IBC, 2019).

\subsection{Methodological Approach}

Data Collection The overall methodical process starts in the first step with data collection. This works in two ways: CityGML files and user input from the graphical user interface (GUI) of urbi+, as shown in Table 1. The GUI also allows the

\begin{tabular}{|l|c|c|}
\hline Data/Information & CityGML & GUI \\
\hline Building geometry (walls, ground, roof) & X & - \\
Building year of construction & X & - \\
Building usage/function & X & - \\
Building roof type & X & - \\
Building's storeys above ground & X & - \\
Building's geographic location (ZIP-Code) & X & - \\
Range of year of construction for assessment & - & X \\
Percentage of heated top floors & - & X \\
Percentage distribution of energy systems & - & X \\
Percentage distribution of heat transfer systems & - & X \\
RSL of all considered TBS components & - & X \\
Primary energy factors of considered energy sources & - & X \\
Percentage share (non-)renewable energy of energy sources & - & X \\
\hline
\end{tabular}

Table 1. Input data sources for the calculations.

definition of further building, energy sources and TBS specific data. The data from the CityGML file is building-specific data, whereas the user input data from the GUI defines average values for all considered buildings. The average values replace missing building-specific data (e.g. exact definition of the heat generator) which in most cases is not available in CityGML data for large building stocks.

Data Processing and Precalculations All collected data is either cached or used for precalculations, to have all data avail- 
able for the following Energy Demand Calculation and Heating Load Calculation:

1) All residential buildings to be assessed are selected according to their use/function and area from the year of construction. 2) The area of wall, ground and roof surfaces is computed based on the geometry of the CityGML model.

3) With the information about roof type, percentage of heated top floors and geometry, the building's net volume is calculated. 4) The information of storeys above ground is used to calculate the building's living area. Therefore, the ground surface area is multiplied with the number of storeys above and the factor 0.89, according to (Bogenstätter, 2007).

5) Using the SharedWallSurface calculator the external wall areas, which are 'shared' between buildings are calculated.

6) Building volumes are calculated using Voluminator, which allows the building volumes to be determined, even if the building topology is not correct.

7) The information about the year of construction of the building is used to sort the building to a specific building age class. According to the specific class, U-values are sourced from a self developed and integrated LCA-database and cached for calculation. Both, the building age classes as well as the U-values are based on the definitions developed by Loga et al. in the TABULA project (Loga et al., 2015).

8) The living area and building age class are used to calculate the approximate window area. As (Heinrich, 2019) defined, according to (Diefenbach et al., 2010) and (Loga et al., 2005), approximate window areas refer to the living area of residential buildings of different building age classes. These values were used for the extrapolation. The resulting window area is distributed evenly over the difference between the total area of all external walls and the shared wall surface area.

9) Based on the geographical location (ZIP-Code), the minimum outside air temperature of the region is taken from the LCA-database. These temperatures are defined in DIN 12831.

Energy Demand Calculation The energy demand calculation for heating and domestic hot water (DHW) is based on DIN V 4108-6 and DIN V 4701-10. Equation 1 describes the first basic step in energy demand calculation. The transmission heat losses are calculated using the U-values and areas of all wall, ground and roof surfaces. The infiltration losses and internal heat gains are calculated by using the building's net volume and multiplying it with a respectively given factor, defined in DIN V 4108-6. The solar gains are calculated by multiplying the window area with an average solar irradiation value from all directions, also according to DIN V 4108-6.

$$
Q_{\mathrm{u}}=Q_{1}-\eta_{\mathrm{p}}\left(Q_{\mathrm{s}}+Q_{\mathrm{i}}\right)
$$

where

$$
\begin{aligned}
& Q_{\mathrm{u}}=\text { useful energy demand }[\mathrm{kWh}] \\
& Q_{\mathrm{l}}=\text { heat losses (transmission }+ \text { infiltration) }[\mathrm{kWh}] \\
& \eta_{\mathrm{p}}=\text { utilization factor }[-] \\
& Q_{\mathrm{s}}=\text { solar heat gains }[\mathrm{kWh}] \\
& Q_{\mathrm{i}}=\text { internal heat gains }[\mathrm{kWh}]
\end{aligned}
$$

In addition, the heat losses as well as the auxiliary energies for the transfer of heat into the room and for heat storage and distribution are added to the useful energy demand. The resulting sum is then multiplied by the product of the heat generator cost figure and the degree of coverage for heating, both defined in DIN V 4701-10. The resulting value is then multiplied by the PEF. This finally results in the PED of the building. For the PED calculation of DHW a useful energy demand of $12.5 \mathrm{kWh} / \mathrm{m}^{2} * \mathrm{a}$ is assumed as the initial value (according to DIN V 4701-10).
The procedure for calculating the primary energy requirement for DHW is the same as for heating. The time component of the heating period of 185 days is taken into account for all calculations.

Heating Load Calculation The heating load calculation refers to DIN 12831. Equation 2 shows the main considered variables. The calculation refers to the minimum temperature of the year. This ensures that the calculated heating load for satisfying the heating energy requirement is guaranteed even on the coldest days. Multiplied by the average efficiency, which results from the percentage share of efficiency of the energy system distribution at building stock level, this gives the required heating load to be covered.

$$
\Phi_{\mathrm{HL}, \text { build }}=\sum\left(\Phi_{\mathrm{T}, \mathrm{i}}\right)+\Phi_{\mathrm{V}, \text { build }}+\sum\left(\Phi_{\mathrm{hu}, \mathrm{i}}\right)-\sum\left(\Phi_{\text {gain, } \mathrm{i}}\right)
$$

where $\quad \Phi_{\mathrm{HL}, \text { build }}=$ heating load building $[\mathrm{kW}]$

$\Phi_{\mathrm{T}, \mathrm{i}}=$ transmission heat losses $[\mathrm{kW}]$

$\Phi_{\mathrm{V} \text {,build }}=$ infiltration heat losses $[\mathrm{kW}]$

$\Phi_{\mathrm{hu}, \mathrm{i}}=$ heating capacity $[\mathrm{kW}]$

$\Phi_{\text {gain }, \mathrm{i}}=$ heat gains $[\mathrm{kW}]$

Dimensioning TBS components All considered TBS components are dimensioned on the basis of different assumptions and norms, which are briefly presented in the following.

The dimensioning or required power of the heat generator is derived from the rounded value of the calculated heating load for heating and DHW multiplied by the efficiency of the considered heat generator. The dimensioning of the oil tank results from dividing the building specific PED by the energy content of heating oil. The energy content of the heating oil is assumed to be $10 \mathrm{kWh} / \mathrm{l}$.

The length of earth probes is calculated by dividing the heat pump extraction capacity by the specific extraction capacity. The heat pump heat extraction rate is calculated from the heating load of the building and the coefficient of performance (COP) of the heat pump. The COP is assumed to have an average value of 3.1. For the specific extraction capacity, an average value of $50 \mathrm{~W} / \mathrm{m}$ across all types of flooring is assumed (see guideline VDI 4640 (VDI, 2019)). The length of the earth collector and the depth of the water well is calculated according to the power of the associated sole-water, or water-water heat pump, based on technical specification in LCA-datasets of the Ökobaudat.

The heating load of the building divided by the average heat output of a radiator results in the length of radiators required to transfer the heat output into the rooms. On the basis of further assumptions regarding average length, height, width and material, the material mass of the radiators can be calculated. When dimensioning the floor heating pipes, the installation distance of the pipes is decisive. A distinction is made between 100 and $200 \mathrm{~mm}$. According to this, the heat output transferred into the room can be calculated. Based on the installation distance and the living area, the material mass of the floor heating pipes can also be calculated. These calculations are also based on technical specification in Ökobaudat LCA-datasets.

Four different pipe systems are used to calculate the pipe lengths for heating. A distinction is made between floor ring type, floor distributor type radiators, floor distributor type, riser pipe type (average values multiplied by the defined share of radiators via GUI) and floor heating (multiplied by a defined share of floor heating via GUI). The respective pipe lengths are calculated by multiplying the living area with specific fixed calculation parameters according to DIN V 18599-5. Three different 
piping systems are used to calculate the pipe lengths for DHW. A distinction is made between decentralized supply (multiplied by a defined share of instantaneous water and gas storage heaters), riser line type and level type (multiplied by the remaining proportion of DHW systems). The respective pipe lengths are calculated by multiplying the living area with specific fixed calculation parameters according to DIN V 18599-8.

The material volume of the pipe insulation for heating and DHW pipes is calculated using the formula for the volume of a hollow cylinder. The diameters used for the calculation are derived from the previously calculated average pipe diameter and the insulation standard, based on the energy standard after refurbishment.

The dimensioning of heat storage tanks for heating water is calculated according to DIN V 18599-5, whereby the daily standby heat loss results from DIN 4701-10.

The dimensioning of heat storage tanks for DHW is calculated according to DIN V 18599-8. The standard defines assumptions for the daily energy demand for hot water, the usage factor and cold and hot water temperatures required for the calculation. The solar collector area is calculated according to (SBZ Monteur, 2020). An average value is calculated for vacuum tube and flat plate collectors. The values for the average German irradiation intensity are sourced from the German meteorological service (DWD, 2020).

Life Cycle Assessment In the LCA, the grey energy and emissions of the TBS components under consideration are then calculated and combined with the energy demand of the use stage and the resulting emissions. The calculated dimensions of the TBS components are offset against the LCA datasets. The LCA data sets from the LCA database naturally refer to the same unit that results from the dimensioning of the TBS components. For each TBS component and LCA stage considered, a specific average value calculated on the basis of the Ökobaudat database is stored in the LCA database. Equation 3 shows the exemplary calculation of the embedded PED for the LCA stages production, EOL and recycling/reuse of the heat generator.

$$
P E_{\text {grey, hg }}=\sum P E_{\mathrm{A} 1-\mathrm{A} 3, \mathrm{C} 2, \mathrm{C} 4, \mathrm{D}, \mathrm{hg}} \times P_{\text {heat generator }}
$$

where

$$
\begin{aligned}
& P E_{\text {grey, heat generator }}=\text { grey primary energy }[\mathrm{kWh}] \\
& P E_{\mathrm{A} 1-\mathrm{A} 3, \mathrm{C} 2, \mathrm{C} 4, \mathrm{D}=\mathrm{LCA}-\mathrm{values}[\mathrm{kWh} / \mathrm{kW}]} \\
& P_{\text {heat generator }}=\text { power of heat generator }[\mathrm{kW}]
\end{aligned}
$$

Result data preparation All relevant calculated (intermediate) results are exported back to an Excel file as well as to the original CityGML file. The values are appended to each building object as newly defined generic attributes. This way they are persistently stored in the model and can be used for visualization purposes and any further investigations and analyses. For visualization appearances of the data are defined using a color scale for the buildings according to their energy demand. For this purpose we have set up a Github repository ${ }^{2}$, with a link to a 3D Web Map Client project, where the results can be viewed in the browser. The coloring of all buildings is set according to their specific PED $\left[\mathrm{kWh} / \mathrm{m}^{2}\right.$ a] from red to green for the status quo and a renovation or development scenario.

\section{VALIDATION}

The methodological block for energy demand calculation has already been validated by comparing the results from energy

\footnotetext{
${ }^{2}$ https://github.com/tum-gis/LCA-TGA
}

demand calculations at the level of individual buildings from $u r b i+$ with results from already established building simulation software IDA ICE (EQUA Solutions AG, 2020) and the already mentioned tool $U M I$. As the results differed only slightly, first results were calculated for a 'small' district with about 300 residential buildings. Again, the calculation results have shown correct trends. However, the investigations have shown that different assumptions and definitions have to be made for the investigations at building stock level than for the calculation at individual building level (Harter et al., 2020).

\section{CASE STUDY MUNICH}

The case study used to apply the method consists of 115,305 residential buildings in Munich, Germany. This covers $81 \%$ of all residential buildings, when comparing the number of residential buildings of 2018 published by Statista (Statista, 2019). The discrepancy in the number of residential buildings is caused by different data sources and data pre-processing steps. While the CityGML LoD2 data where provided by the Bavarian State Office for Digitization, Broadband and Surveying ${ }^{3}$ (Project: Geomassendaten), all other building-specific parameters (e.g. year of construction) where provided by the Planning Department of the Bavarian State Capital Munich ${ }^{4}$. The matching of data was carried out by using a geometric intersection operation between the building ground surfaces and house coordinates with statistical values attached as attributes, which resulted in losing some unmatched buildings. In addition, the parameters required for calculations were not available for all buildings, which also resulted in the exclusion of further buildings. The following average values resulting from the Data Processing and Precalculations characterize the building stock under investigation.

\subsection{Definitions}

1) Average number of floors is 2.6. (min: 1, max: 29). Since the citizens' decision in 2004, no buildings taller than $100 \mathrm{~m}$ are allowed to be built in Munich, the tallest residential building has 29 floors.

2) Average living space per building $415 \mathrm{~m}^{2}$, i. e. average $130 \mathrm{~m}^{2}$ living space per floor.

3) Mean building volume $1,522 \mathrm{~m}^{3}$, i.e. mean value $499 \mathrm{~m}^{3}$ volume per floor (without consideration of interior walls and intermediate ceilings).

These data seem consistent when comparing the distribution of buildings over the age classes in Figure 2 with the distribution of building volumes over their living area in Figure 1. Figure 2 shows that about $35 \%$ of the residential buildings were constructed before 1957 and that building age class 4 (bac 4) is the most strongly represented age class with about $21 \%$. This is likely due to the fact that the shortage of materials caused by the Second World War was slowly overcome at the beginning of the bac 4. Figure 1 shows a correlation between building volume and living area. In addition, the distribution shows that buildings with a low building age class, i. e. older buildings, have a larger volume per square meter of living area. That is plausible, because in older buildings, high ceilings and fewer floors were preferred. The consideration of the distribution of the building age classes in the context of the distribution of the

\footnotetext{
3 https://www.ldbv.bayern.de/

4 https://www.muenchen.de/rathaus/Stadtverwaltung/Referat-fuerStadtplanung-und-Bauordnung.html
} 


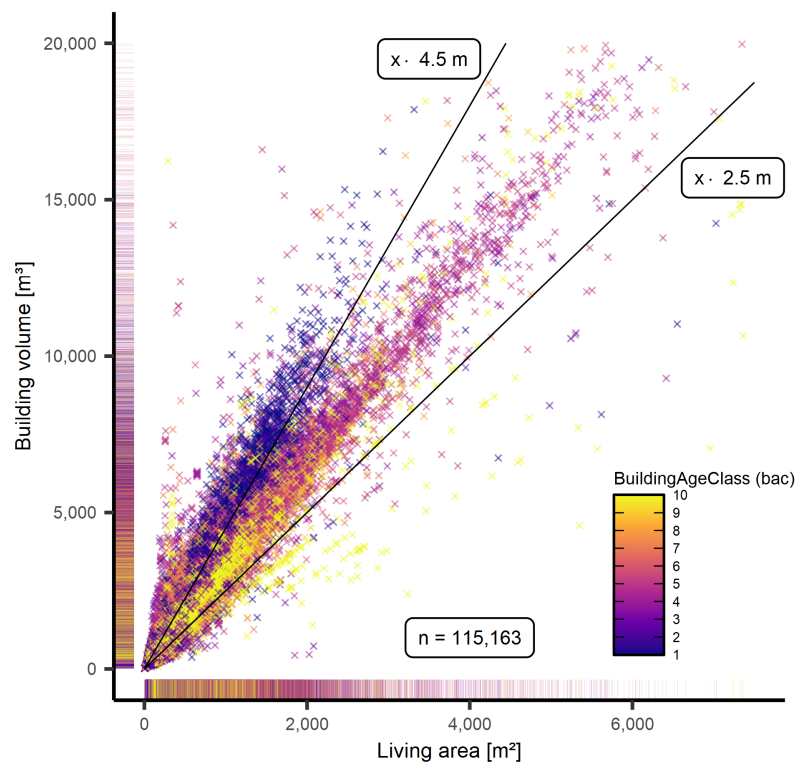

Figure 1. Distribution of building volume vs. living area. 147 buildings with volume $>20,000 \mathrm{~m}^{3}$, living area $>7,500 \mathrm{~m}^{2}$ filtered out for better visibility. The range of plausible floor heights $(2.5-4.5 \mathrm{~m})$ lies between the two black lines.

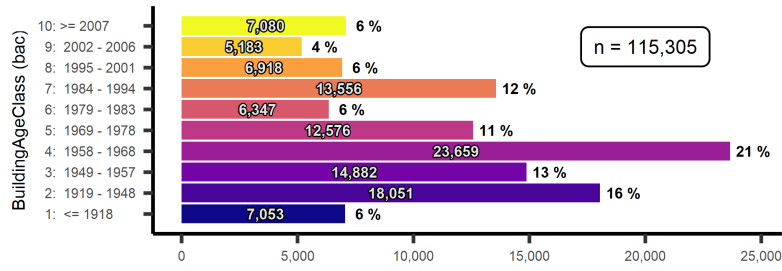

Figure 2. Distribution of buildings over building age classes. No filtering as in Figure 1 applied.

ratios between building volume and living area as well as the already mentioned average values thus result in a coherent picture. However, the number of buildings with ceiling heights of more than 4.5 meters has to be examined more closely for future investigations, as there may be discrepancies between the number of floors and the building height between the data of the Bavarian State Office for Digitization, Broadband and Surveying and the Planning Department of the Bavarian State Capital Munich (different up-to-dateness of the data).

\subsection{Parameter Definition for Simulation}

In order to carry out a life cycle based assessment of the building stock for the status quo and two refurbishment scenarios, the input parameters for the simulations must be defined first. The development period of both refurbishment scenarios is set to 30 years, which means that until 2050 all residential buildings are refurbished to defined values. The definitions used for the calculation are based on assumptions that serve to explain the methodological approach (status quo $=$ scenario 0 ; development scenario 1; development scenario 2):

1) percentage heated top floors: $20 \% ; 80 \% ; 80 \%$

2) DHW: $20 \%$ gas, $40 \%$ oil, $10 \%$ gas-storage heaters, $10 \%$ electric flow heaters; $20 \%$ gas, $30 \%$ heat pumps (hp), $40 \%$ solar, $10 \%$ district heating; $30 \%$ solar, $70 \%$ district heating.

3) heating: $80 \%$ gas, $20 \%$ oil; $20 \%$ gas, $40 \%$ air-water hp, $5 \%$ hp earth collector, $5 \%$ hp earth probe, $20 \%$ water-water hp, $10 \%$

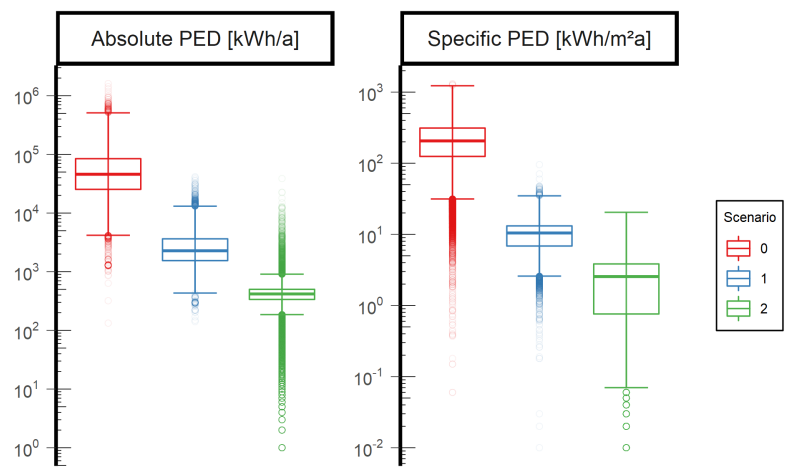

Figure 3. Comparison of absolute and specific PED for the three scenarios.

biomass; $100 \%$ district heating

4) heat transfer system: $100 \%$ radiators; radiators $50 \%$, floor heating $50 \%$; floor heating $100 \%$

5) $\mathrm{U}$-values $\left[\mathrm{W} / \mathrm{m}^{2} \mathrm{~K}\right]$ : according to $b a c$ (see Subsection 3.2); wall: 0.24 , window: 1.3 , roof: 0.24 , base plate: 0.35 ; wall: 0.15 , window: 0.85 , roof: 0.15 , base plate: 0.3

6) g-value Window [-]: according to $b a c ; 0.6 ; 0.5$

7) PEFs: gas: 1.1 , oil: 1.1 ; gas: 1.1 , environmental heat and solar radiation: 0.0 , biomass: 0.2 , electricity: 0.5 , district heating: 0.5 ; solar radiation: 0.0 , district heating: 0.1 .

8) reference service life [years]: gas-boiler: 20, oil-boiler 20 , gas-storage heaters: 20, instantaneous flow heaters: 15 , DHW and heating pipes: 50 , pipe insulation: 25 , heat storage tanks: 25, radiators: 50; gas-boiler: 20, all heat-pumps: 20, biomassboiler 20, earth probes and collectors: 50, DHW and heating pipes: 50 , pipe insulation: 25 , heat storage tanks: 25 , radiators and floor heating: 50; district heating connection station: 20 , floor heating: 50, DHW and heating pipes: 50, pipe insulation: 25, heat storage tanks: 25 .

9) share of renewable and non-renewable energy of energy sources: gas: $10 \% / 90 \%$, oil: $0 \% / 100 \%$; gas: $30 \% / 70 \%$, electricity: $50 \%, 50 \%$, environmental heat and solar radiation: $100 \%$, 0\%, biomass: $100 \%, 0 \%$; district heating: $90 \%, 10 \%$, solar radiation: $100 \%$.

\subsection{Results}

Figure 3 shows the improvement of the absolute and specific PED of the buildings' use stage through the refurbishment of the entire building stock in the two scenarios (scenario 1 and 2 ) on a logarithmic scale. The results of the status quo (scenario 0) are shown next to it as a reference value. It can be seen that the fluctuation range of the values changes according to the ratio of the numbers within a scenario and that a significant reduction can be achieved for both the absolute and the specific PED $(-96 \% \&-99 \%)$. The mean value of the specific PED has fallen from 238 to 11 , or $3 \mathrm{kWh} / \mathrm{m}^{2}$ a and the mean value of the absolute PED from 6,5377 to 2,823, or $361 \mathrm{kWh} / \mathrm{a}$. Among other things, this is due to the very strongly improving primary energy factors (PEFs). Table 2 shows the changes of the different TBS component dimensions in the different scenarios, referring always to the average values over all buildings. Due to the reduction of the heating load and the use of efficient and modern heat generator technologies and systems, the connected load of the heat generators has been reduced from $43 \mathrm{~kW}$ to $14 \mathrm{~kW}$ and $11 \mathrm{~kW}$ respectively. Oil tanks are only existing for the status quo and account for an average volume of 2,018 liters. DHW's storage accounts for around $95 \%$ of hot water 
storage (heating \& DHW). The basic need for DHW does not change with a building refurbishment, only the efficiency and the type of technical connection of the systems that produce the DHW. Because of this, the average value only decreases slightly over the scenarios. Solar systems for DHW exist only in scenario $1 \& 2$. The number of square meters is adjusted mainly on the basis of the defined degree of coverage for the generation of DHW from solar systems. The earth collectors, probes and pipes for the sole-water and water-water heat pumps only appear in scenario 1 . The earth collectors are logically much longer than the probes. The mass of the pipes of the water-water heat pump is calculated based on the calculation of the LCA. By adapting the heat transfer through radiators, their mass portion is reduced when comparing status quo with scenario 1 . The opposite is the case when calculating the length of the floor heating pipes. Both are caused by the before mentioned definition of the heat transfer system. The length of DHW pipes, given in meters per square meter of living area, increases in comparison. This is due to the fact that in the status quo more decentralized energy systems were used for DHW provision, which require significantly shorter pipe lengths and are installed downstream at the tap. With the switch to more decentralized energy systems for DHW generation, the average pipe length increases. The length of heating pipes, also given in meters per square meter of living area, is the exact opposite. This is due to the fact that in the status quo, $100 \%$ of the heating is provided by radiators and therefore pipes have to be added to each radiator installed. With the increasing use of floor heating systems, the average pipe length decreases, as pipes only have to be laid per heated room. The pipe insulation adapts to the sum of these two values and is expressed in cubic meters per meter of pipe length. The embedded energy and emissions of the manufac-

\begin{tabular}{|c|c|c|c|}
\hline TBS component & Status quo & Scenario 1 & Scenario 2 \\
\hline heat generator $[\mathrm{kW}]$ & 43 & 14 & 11 \\
\hline oil tank [1] & 2,018 & - & - \\
\hline heat storage tank [1] & 469 & 457 & 453 \\
\hline solar $\left[\mathrm{m}^{2}\right]$ & - & 1.68 & 10.12 \\
\hline earth collector $[\mathrm{m}]$ & - & 34.2 & \\
\hline earth probe $[\mathrm{m}]$ & - & 9.3 & - \\
\hline pipes water-water hp [kg] & - & 4.11 & - \\
\hline radiators $[\mathrm{kg}]$ & 1,489 & 349 & - \\
\hline pipes floor heating $\left[\mathrm{m} / \mathrm{m}^{2}\right]$ & - & 2.17 & 1.33 \\
\hline pipes DHW $\left[\mathrm{m} / \mathrm{m}^{2}\right]$ & 2.9 & 3.2 & 3.2 \\
\hline pipes heating $\left[\mathrm{m} / \mathrm{m}^{2}\right]$ & 3.62 & 3.33 & 3.03 \\
\hline pipes insulation $\left[\mathrm{m}^{3} / \mathrm{m}\right]$ & 0.0023 & 0.0022 & 0.0011 \\
\hline
\end{tabular}

Table 2. Dimensions TBS components.

turing, use and EOL stage are calculated on the basis of the building-specific dimensions of the TBS components. If these values are combined with those of the use stage, i. e. for the operation of the building, and considered over the course of the year over the development period of the refurbishment scenarios, the results are as shown in Figure 4. Over the course of 30 years, around 3,843 residential buildings are refurbished each year, so that by 2051 all buildings have been refurbished. The graph clearly shows the significant reduction in the total PED (heating tpe_h and DHW tpe_dhw) of all building-specific use stages as a result of the refurbishment. In addition, the total amount of embedded energy tpe_e for the EOL of old systems to be disposed in the course of refurbishment and manufacturing of the new systems is also listed. It can be seen that the course is much steeper in the first years and then makes a small bend around the year 2040. This is because the selection of buildings described in chapter 3.1 will first refurbish all the old buildings with a high specific and absolute PED. As soon as

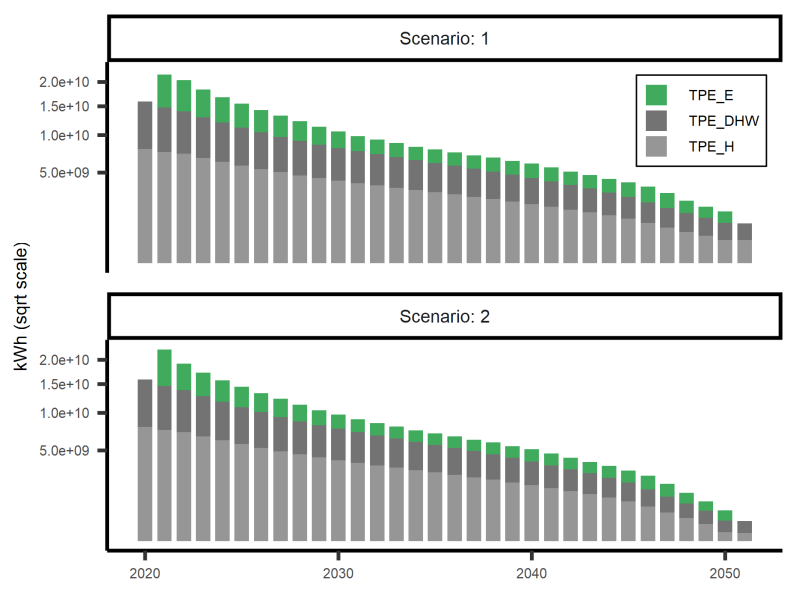

Figure 4. Comparison PED (TPE_H + TPE_DHW) with the embedded PED (TPE_E) for both development scenarios.

most of these buildings have been refurbished, the course will flatten out. The small bend around the year 2040 results from the fact that the TBS components of the buildings which have been renovated in the first years already have to be replaced, because they have reached the end of their RSL. A closer look at the figures of scenario $1 \& 2$ shows that in the third year of refurbishment, i. e. 2023, the investment in embedded energy will have amortized by comparison with the savings achieved. This will not change over the further course of the refurbishment scenarios. However, it must be noted that embedded energy is not taken into account for the renovation of the building envelope which must be investigated in following research. Even if there is a significant reduction in the energy demand through the ambitious renovation of all residential buildings to a high energy standard and with efficient technologies in the two scenarios, a PED of around 325.5 million $(\mathrm{m}) \mathrm{kWh}$ in scenario 1 and $41.5 \mathrm{~m} \mathrm{kWh}$ in scenario 2 still remains. This results in around $255.4 \mathrm{~m} \mathrm{~kg} \mathrm{CO}$-eq./a for scenario 1 and $71.4 \mathrm{~m} \mathrm{~kg} \mathrm{CO}$-eq./a for scenario 2 (calculated on the basis of Ökobaudat-database values) and this does not yet include embedded energy for the building construction.

\section{DISCUSSION}

The case study shows, that the introduced method can be applied to large building stocks by using semantic 3D city models. Due to the standardization (CityGML) of the city model the approach can easily be applied to other cities. In general, it can be seen that if we assume that all residential buildings will be refurbished to an ambitious energy standard, there will be a significant reduction in PED and emissions. However, it is very difficult to achieve a climate-neutral building stock, especially when including the embedded energy resulting from LCA. Even if the PED can be reduced by using renewable energy technologies, PEDs and emissions are still generated in the manufacturing, use and EOL stage. With regard to the refurbishment of the TBS, however, it can be said that, at least in the scenarios considered, a rapid amortisation of the embedded energies has been achieved. In order to focus more strongly on the use of solar thermal energy and photovoltaics, it is planned to integrate an already developed solar tool into the framework of urbi+. In the course of a refurbishment, not only the TBS components but also the building envelope will be refurbished, thus the LCA of the building construction will be integrated in future 
work. Experience has shown that a large proportion of embedded energy and emissions are generated in this process. Apart from this, the life cycle cost (LCC) assessment plays an important role in construction projects. Especially with regard to the upcoming pricing of $\mathrm{CO}_{2}$-emissions, it makes sense to integrate LCC into urbit. A big advantage of the introduced method is that the results are fed back to the CityGML building objects as generic attributes. This way, the result figures are persistently stored in the city model linked to the specific real world objects they belong to and are thus available for subsequent analysis including other data source or software. One example of this approach can be found in the work of (Fuchs, 2018), where reference values for solar heat gains in the heat demand calculation have been replaced with results of the solar potential analysis tool described in (Willenborg et al., 2017). By using the more detailed results of the solar tool including the 3D topography surrounding the buildings, the accuracy of heat demand calculation could be improved significantly. Moreover, the results can easily be visualized using the 3DCityDB WebMapClient.

\section{ACKNOWLEDGEMENTS}

The authors would like to thank Ordnance Survey GB (www.ordnancesurvey.co.uk) and 1Spatial (www.1spatial.com) for sponsoring the publication of this paper.

\section{REFERENCES}

Biljecki, F., Stoter, J., Ledoux, H., Zlatanova, S., Çöltekin, A., 2015. Applications of 3D City Models: State of the Art Review. ISPRS International Journal of Geo-Information, 4(4), 2842-2889.

Bogenstätter, U., 2007. Flächen- und Raumkennzahlen. www.ifbor.eu/3.html. Online; accessed 2020-02-12.

Cabeza, L. F., Rincón, L., Vilariño, V., Pérez, G., Castell, A., 2014. Life cycle assessment (LCA) and life cycle energy analysis (LCEA) of buildings and the building sector: A review. Renewable and Sustainable Energy Reviews, 29, 394-416.

Chen, Y., Hong, T., Piette, M. A., 2017. Automatic generation and simulation of urban building energy models based on city datasets for city-scale building retrofit analysis. Applied Energy, 205, 323-335.

Coccolo, S., Mauree, D., Kämpf, J., Scartezzini, J.-L., 2016. Integration of outdoor human comfort in a building energy simulation database using CityGML Energy Ade. SBE Regional Conference Zurich.

Diefenbach, N., Cischinsky, H., Rodenfels, M., Clausnitzer, K.-D., 2010. Datenbasis Gebäudebestand. Datenerhebung zur energetischen Qualität und zu den Modernisierungstrends im deutschen Wohngebäudebestand. Institut Wohnen und Umwelt (IWU). Darmstadt.

DIN EN 12831-1:2017-09, 2017. Energy performance of buildings Method for calculation of the design heat load - Part 1.

DIN EN 15978:2012-10, 2012. Sustainability of construction works - Assessment of environmental performance of buildings.

DIN EN ISO 14040:2009-11, 2009. Environmentalmanagement - Life cycle assessment - Principles and framework.

DIN V 18599-5:2018-09, 2018. Energy efficiency of buildings - Calculation of the net, final and primary energy demand for heating, cooling, ventilation, domestic hot water and lighting - Part 5.

DIN V 18599-8:2018-09, 2018. Energy efficiency of buildings - Calculation of the net, final and primary energy demand for heating, cooling, ventilation, domestic hot water and lighting - Part 8 .

DIN V 4108-6:2003-06, 2003. Thermal protection and energy economy in buildings - Part 6 .

DIN V 4701-10:2003-08, 2003. Energy efficiency of heating and ventilation systems in buildings - Part 10.

DWD, 2020. Deutscher Wetterdienst - Globalstrahlungskarten www.dwd.de/DE/leistungen/solarenergie/lstrahlungskarten_mi.html. Online; accessed 2020-04-11.

EQUA Solutions AG, 2020. IDA ICE - Simulation Software - EQUA. https://www.equa.se/de/ida-ice. Online; accessed 2020-04-02.

EU Commission, 2018. A Clean Planet for all - A European strategic long-term vision for a prosperous, modern, competitive and climate neutral economy. Technical report, European Commission, Brussels.
Federal Ministry of IBC, 2019. Federal Ministry of Interior Building and Community (IBC) - Sustainable Building Assessment System (BNB) https://www.bnb-nachhaltigesbauen.de/. Online; accessed 2019-08-28.

Federal Ministry of IBC, 2020. Federal Ministry of Interior Building and Community (IBC) - ÖKOBAUDAT. www.oekobaudat.de/. Online; accessed 2020-04-05.

Fuchs, D., 2018. Berechnung des Energiebedarfs von Wohngebäuden auf Basis von semantischen 3D-Stadtmodellen am Beispiel der Gemeinde Poing. Bachelorarbeit, Technische Universität München, München.

German Federal Ministry of EAE, 2013. German Federal Ministry of Economy Affairs and Energy (EAE) - Energy Saving Ordinance (EnEV). Harter, H., Banihashemi, F., Kierdorf, D., Vollmer, M., Lang, W., 2020. Comparison of different energy demand calculation models on urban scale. (Accepted at BauSim2020 Conference in Graz).

Heinrich, M. A., 2019. Erfassung und Steuerung von Stoffströmen im urbanen Wohnungsbau. Dissertation, Technical University of Munich.

Kaden, R., 2014. Berechnung der Energiebedarfe von Wohngebäuden und Modellierung energiebezogener Kennwerte auf der Basis semantischer 3D-Stadtmodelle. Dissertation, TU München.

Kolbe, T. H., 2009. Representing and Exchanging 3D City Models with CityGML J Lee, S. Zlatanova (eds), 3D Geo-Information Sciences, Lecture Notes in Geoinformation and Cartography, Springer Berlin Heidelberg, Berlin, Heidelberg, 15-31.

Loga, T., Diefenbach, N., Knissel, J., Born, R., 2005. Entwicklung eines vereinfachten, statistisch abgesicherten Verfahrens zur Erhebung von Gebäudedaten für die Erstellung des Energieprofils von Gebäuden. Kurzverfahren Energieprofil.

Loga, T., Stein, B., Diefenbach, N., Born, R., 2015. Deutsche Wohngebäudetypologie - Beispielhafte Maßnahmen zur Verbesserung der Energieeffizienz von typischen Wohngebäuden. IWU, Darmstadt.

Nouvel, R., Bahu, J.-M., Kaden, R., Kaempf, J., Cipriano, P., Lauster, M., Häfele, K.-H, Munoz, E., Tournaire, O., Casper, E., 2015a. Development of the citygml application domain extension energy for urban energy simulation. Building Simulation 2015 - 14th IBPSA Conference, India.

Nouvel, R., Brassel, K.-H., Bruse, M., Duminil, E., Coors, V., Eicker, U., Robinson, D., 2015b. SimStadt, a new workflow-driven urban energy simulation platform for CityGML city models. Proceedings of International Conference CISBAT 2015, LESO-PB, EPFL, 889-894.

Open Geospatial Consortium, 2012. OGC City Geography Markup Language (CityGML) Encoding Standard 2.0.

Reinhart, C., Dogan, T., Jakubiec, A., Rakha, T., Sang, A., 2013. UMI - an urban simulation environment for building energy use, daylight and walkability. 13th IBPSA Conference, Chambéry, France.

Remmen, P., Lauster, M., Mans, M., Osterhage, T., Müller, D., 2016. CityGML import and export for dynamic building performance simulation in modelica. Proceedings of BSO Conference, Newcastle University. SBZ Monteur, 2020. Wirkungsgrad von Solaranlagen. www.sbzmonteur.de/gut-zu-wissen/wirkungsgrad-von-solaranlagen. Online; accessed 2020-04-11.

Sindram, M., Machl, T., Steuer, H., Pültz, M., Kolbe, T. H., 2016. Voluminator 2.0 - Speeding up the Approximation of the Volume of Defective 3D Building Models. ISPRS Annals, III-2.

Statista, 2019. Wohngebäude in München - Bestand bis 2018 https://de statista.com/statistik/daten/studie/260455/umfrage/bestand-anwohngebaeuden-in-muenchen. Online; accessed 2020-04-15.

UN Environment and IAE, 2017. Towards a zero-emission, efficient, and resilient buildings and construction sector.

VDI, 2019. Verein Deutscher Ingenieure (VDI) - Thermal use of the underground Ground source heat pump systems VDI 4640 Blatt 2.

Walter, E., Kämpf, J., 2015. A verification of CitySim results using the BESTEST and monitored consumption values. Proceedings of $2 n d B S A$ Conference.

Weiler, V., Harter, H., Eicker, U., 2017. Life cycle assessment of buildings and city quarters comparing demolition and reconstruction with refurbishment. Energy and Buildings, 134.

Willenborg, B., Sindram, M., Kolbe, T. H., 2017. Applications of 3d city models for a better understanding of the built environment. M. Behnisch, G. Meinel (eds), Trends in Spatial Analysis and Modelling, Geotechnologies and the Environment, Springer International Publishing, Berlin, Heidelberg, 167-191.

Yao, Z., Nagel, C., Kunde, F., Hudra, G., Willkomm, P., Donaubauer, A., Adolphi, T., Kolbe, T. H., 2018. 3DCityDB - a 3D geodatabase solution for the management, analysis, and visualization of semantic 3D city models based on CityGML. Open Geospatial Data, Software and Standards. 